\title{
Use of Second-Hand Clothing and Construction of Health Risks for Women in Abidjan (Cote D'ivoire) AGOBE Ablakpa Jacob*
}

Master-Assistant, Institute of Ethno-Sociology (IES) -UFR-SHS, Félix Houphouët-Boigny University Côte d'Ivoire

DOI: $10.36347 /$ sjahss.2021.v09i04.001

| Received: 23.12.2020 | Accepted: 11.01.2021 | Published: 13.04.2021

*Corresponding author: AGOBE Ablakpa Jacob

\section{Abstract}

This study aims at analysing the social logic of the use of second-hand underwear by the women in Abidjan with regard to the construction of the health risks involved. The text is based on the results of a qualitative study conducted in Abidjan. It emerges from this investigation that the use of second-hand pants among women in Abidjan is guided by various social representations of health risk. These representations can be grouped around two main types of ideological references: ideologies based on knowledge of health risk [1] and ideologies of acceptability of health risk [2]. These ideological productions are socially marked, and are mobilised by the actors to justify their behaviour "at risk" from the use of second-hand pants.

Keywords: Use of pants, Thrift stores, Health risks, Women, Côte d'Ivoire.

Copyright $(2021$ The Author(s): This is an open-access article distributed under the terms of the Creative Commons Attribution 4.0 International License (CC BY-NC 4.0) which permits unrestricted use, distribution, and reproduction in any medium for non-commercial use provided the original author and source are credited.

\section{INTRODUCTION}

The purchase and use of second-hand clothing has become increasingly successful since a few years following a context of global economic crisis and a change in the economic environment mentalities. The second-hand market has long been associated with disadvantaged consumers who use it out of economic necessity and thus with impoverishment. Nowadays, with the cultural evolution in commerce and consumer behaviour, second-hand purchasing appears to be a matter of choice as well [1].

A study conducted on the origin of the marketing of second-hand clothes reveals the sources of supply and the trajectories of the fripe on a global scale. At indeed, "from the 19th century, the fripe was the subject of international trade" [2]. Thus in 1854, 1,260 tonnes of new and old undifferentiated clothing were exported from France (and in 1867, 1,838 tonnes). This is often military clothing, but not only. "The enormous quantities and extreme profitability of these exports signal a perfectly structured trade on a global scale" (M. Charpy, op. cit.).

In this vein, the history of the fripe began in Europe. Indeed, following the Second World War, the old continent is on its knees and America, which emerges enriched from the conflict, undertakes a vast movement of generosity towards its European cousins. As a result, donations of used clothing began to flow in. Then, the purchasing power of the European population improved, the price of textiles fell and used clothes found other destinations. Thus, after Europe, the African territories, first as colonies and then as fledgling states, quickly became an interesting outlet for clothing that Westerners no longer wanted. Charitable organisations began to collect these used clothes, no longer necessarily to give them to the poor, but to sell them and generate small financial resources [3].

${ }^{1}$ Ideologies linked to ignorance of the damage associated with the danger, ideologies of non-exposure to health risk or the supposed control of risks with regard to sterilisation procedures and the risk/effect relationship.

${ }^{2}$ Ideologies linked to economic constraints and quality, addiction, social learning about risk within the family environment and with peer groups, ideologies of attributing health risk to divine will. 
As Africa is the new destination for the fripe, a new mode of consumption will emerge. In fact, the development of the fripe is one of the symbols of an Africa in transformation, characterised by the permanent capacity of its inhabitants to adapt to the changing contexts. The comparison of the different commercial activities linked to the fripe, the multiple journeys of the operators, and the different perceptions of this product by the populations allows us to put forward hypotheses on the relationship to second-hand clothes in Africa. Thus, the development of the fripe in Africa has made it possible to relaunch a used product in a new cycle of consumption by giving it a new market value. Some authors have highlighted the effervescence of the second-hand clothing sector in Africa in the 1990s. Developing countries became new markets as Western countries were no longer able to absorb all these devalued products on their own. A do "kaflê, yougou yougou, troutrou nou, klou fâ"or broad in Côte d'Ivoire [4]. "Since the 'transition' of 2000 in Côte d'Ivoire and the emergence of recurrent political unrest from 2002 onwards, the trade in rags seems to have stabilised" (S. Bredeloup and J. Lombard, op. cit.). Thus, second-hand clothing is a sector of activity that is booming in Côte d'Ivoire, mainly in the economic capital, where many people obtain their supplies [5].

Moreover, since the devaluation of the CFA franc, the economic situation of the Abidjanese, already in a bad way, has worsened because of the socioeconomic and political crises of the 2000s. The majority of Abidjanese therefore find themselves in financial difficulty nowadays. They will use all sorts of means of survival at the risk of their health or their lifestyle [6].

Therefore, the use of second-hand clothing is a health risk practice. It is therefore possible to contract diseases while wearing second-hand clothes. Usually, these are skin-related illnesses. Some people have allergies when they wear second-hand clothes. These allergies are certainly related to the products used in the countries of origin to treat the garments and allow them to maintain their shine right up to the final recipient.

These products can have negative effects on the bodies of people with fragile skin. They may have pimples on the body or itchy skin [7]. In addition, more and more women are adopting second-hand clothing as part of their wardrobe dresses. What attracts the most attention are underwear, especially pants. Second-hand shops they love. However, the use of this underwear constitutes a danger. For human health [8]. The health problems associated with second-hand undergarments are of primary concern when these garments are unhygienic, contagious and provide a nest of microbes [9]. Thus, in an interview with Fily Sissoko published on February 08, 2014 on Maliweb.net, Dr Camara, a doctor at the Cscom in Magnambougou, says that the actresses in the reuse of the used boxer shorts are exposed to dermatosis with the appearance of scabies, fungus and mycosis. (Fungal infections) and vaginitis (inflammation of the lining of the vagina). Resulting in white discharge. The long-term corollary is genital infections. High which can be complicated by tubal obstruction which is a source of primary and secondary infertility secondary.

In this vein, during his visit to Brazil in 1935 , Claude Levy-Strauss noted an demographic decline of the indigenous population in the State of Sao Paolo, which he links to the collection in the hospitals, secondhand clothes infected with smallpox victims that are marketed along the paths frequented by the natives who reuse them [3]. So it is not surprising to see in Abidjan, the amateurs of the fripe rummage in oubelles in order to collect these clothes to then resell them. Their washing is often done in rivers and chlorinated afterwards in order to give them back their shine. These practices can be observed on the Yopougon Adjamé axis in the watercourse that flows from the Ebrié lagoon near the SI Company. Concrete towards the Banco forest. It is obvious that these resold and reused clothes bear marks of contagious miasmas with regard to their state of hygiene.

In Abidjan, we note a recurrence of the use of second-hand pants among women. A series of observations conducted in the neighbourhoods enabled us to to notice the stalls of second-hand underwear piled up on the ground or displayed on open-air tables, which are very popular with women. These second-hand pants are displayed in hygienic conditions that leave nothing to be desired. In this vein, a young student in school uniform, after classes decides to go to the Sicogi market to renew his wardrobe. Among the choices of thrifty underwear made, two of them show suspicious stains in certain places. But the girl lets it be known that after washing with soap and water, she will be safe (Field observation).

As a result, these women are unanimously aware of the health risks involved, which is made clear by the lack of hygiene in the second-hand underwear shops due to the conditions of storage, the products used for storage and the state of health of previous users. However, they are always crowded around the second-hand underwear stalls and make their choices. We often see them sorting out these underwear on the pavements without embarrassment and even doing tests to make sure they have made the right choice. Their desire is to get underwear that suits them at all costs. The use of second-hand underwear is a health risk practice and therefore poses a problem of health awareness.

In fact, the idea of consciousness is associated with that of prudence and that health consciousness refers to the esteem and concern for oneself that are manifested in the relationship of the human being to his health, knowing that for every normally constituted and 
socialised individual human life is an inalienable value because it is precious. Every individual takes care of his health, but with the resources of his environment [10]. In other words, the use of second-hand pants is a principle of problematisation of clothing practices by opening up the notion of health awareness and the construction of risks. The research question that guided this study is therefore the following: What are the social logics of the use of second-hand underwear by women in Abidjan in relation to their awareness of the health risks involved? Specifically, what knowledge do women in Abidjan have of the health risks associated with the use of second-hand underwear? What are the ideologies of acceptability of the health risk of using second-hand pants mobilised by women in Abidjan? The hypothesis underlying the main points of this study is that the use of second-hand pants by women in Abidjan is a socially constructed reality in relation to representations of health risk. This study analyses the social logic behind the use of second-hand pants by women in Abidjan in relation to their awareness of the health risks involved. The specific objectives that follow from the general objective revolve around two points: (i) To determine the knowledge of the health risks associated with the use of second-hand pants; (ii) To identify the ideologies of risk acceptability developed by women.

\section{Theoretical approach}

Drawing on the theory of social constructivism, a current in contemporary sociology, Peter Berger and Thomas Luckman [11] consider that: "Reality is socially constructed and that the sociology of knowledge must analyse the process in which this occurs. The key terms in these assertions are 'reality' and 'knowledge', terms which are not only topical in everyday language, but which have a long history of philosophical research behind them. We need not enter here into a discussion of the semantic complexities of the everyday or philosophical use of these terms. It will suffice, for our purposes, to define "reality" as a quality belonging to phenomena that we recognise as having a being independent of our own will (we cannot "want" them), and to define "knowledge" as the certainty that phenomena are real and that they possess specific characteristics". Social reality and social phenomena as constructed, i.e. created, institutionalised and subsequently transformed into traditions. Thus the use of second-hand pants and the health consciousness associated with this conduct appear to be social realities constructed in two ways by the women of Abidjan: objectively from information received in the field.

Indeed, this study aims to make an effective contribution, a major one in that most of the studies carried out in the context of second-hand clothing stores have dealt in general with the motivations for buying second-hand clothes or the brakes associated with them, and not with a particular type of clothing. As a result, studies on the construction of the health risk associated with this purchasing behaviour are virtually nonexistent to our knowledge. For example, there is the study by (L. Bamba, op cit) on the health risks of smuggled goods on the populations of Abidjan and the study by (M-S. Wera, op cit) entitled: Analysis of barriers to the purchase of second-hand clothes. The aim of this study is therefore to understand the social logic behind the construction of the health risks associated with the use of second-hand pants, with a view to making our ongoing contribution to the construction of this cornerstone.

\section{METHODOLOGY}

\section{Site and survey participants}

The study ran from 10 January 2020 to 28 January 2020 inclusive. This study was carried out in the city of Abidjan. The choice of this geographical area is explained by the fact that Abidjan is the economic capital of Côte d'Ivoire, a social setting where risky behaviour is becoming more and more prevalent, and also by the fact that the second-hand clothes sold there are sold to customers who are mostly women. Thus, risk behaviours generally emerge in a globalised environment, with increasing mobility and areas of very high human concentration. For us, it is a question of identifying the resource persons who are in touch with the social reality we are studying. Having said that, the question we are asking ourselves here is who to interview for the collection of information. It relates to all those who are in direct and indirect contact with the field of this study. Thus, the study concerned (02) categories of actors who make up our target population: acquirers of second-hand underwear from the Sicogi market and (tes) traders in second-hand underwear.

\section{Data collection techniques and tools}

The study has a qualitative perspective as it looks at the social logics underlying the use of thrifty pants by women who frequent Abidjan's markets. As a result, the following techniques are used: documentary research, direct observation, individual and in-depth interviews, and the recording and transcription of data from the field. We have therefore used the interview guide as a data collection tool. According to [12], the technical pole deals with the procedures for collecting information and transforming it into data relevant to the general problem. Its function is to identify "the facts" in significant systems, by means of protocols for the experimental highlighting of these empirical data. It is therefore the place to specify the various techniques used to collect the data for this study. These are documentary research, direct observation and interviews.

\section{Method of analysis and data processing}

In order to understand the social logics of the construction of health risks linked to the use of secondhand underwear, the approach adopted is that of content analysis. The object of content analysis is communication, which is the fundamental process of 
the formation of social representation [13]. According to [14], content analysis allows, when it concerns rich and penetrating material, to harmoniously satisfy the requirements of methodological rigour and inventive depth which is not always easily reconcilable. It should be pointed out that content analysis contains several analysis techniques including discourse analysis, thematic analysis and analysis of verbal behaviour. For this study, the appropriate analysis is thematic analysis. Indeed, thematic analysis is a process that consists of cutting across the corpus. It involves using the theme as the unit of division. The thematic analysis enabled us to bring out the opinions of the respondents on each theme in relation to the objectives of the study.

\section{RESULTS}

Several scientific works have focused on the motivations for the consumption of used products, mainly in the field of second-hand clothing. In the context of our study, the emphasis will be on health awareness in relation to the use of second-hand underwear. This is a phenomenon that can be observed in several societies, but in a different way depending on each area. The causes also vary according to the social universe. What particularly caught our attention are the health damages that can be caused by the use of secondhand clothing.

This study will focus on the social logics of constructing the meaning of health risks in relation to the use of second-hand underwear. To do this, we are interested in three categories: economic factors, sociocultural burdens and the degree of health awareness.

\section{Awareness of the health risk, a factor representing the risk of the use of second-hand pants}

\section{Ignorance of damage associated with hazards}

The identification of the dangers perceived by social actors, which in turn leads to damage, is an important factor in assessing knowledge of the health risk. According to Dr [15], a doctor at the Cscom in Magnambougou (Mali), the use of second-hand pants by women exposes them to dermatosis with the appearance of scabies, fungus (fungal infections) and vaginitis (inflammation of the mucous membrane of the vagina) leading to white discharge. The long-term corollary is upper genital infections which can be complicated by tubal obstruction, a source of primary and secondary infertility. On the basis of our field survey, we underline a lack of knowledge of the damage associated with the dangers in Yopougon Sicogi women. This is illustrated by the following comments: In any case, I know that when you use second-hand underwear there are risks, but I don't know too much (Excerpt from an interview with K. E, user of Sicogi-Abidjan second-hand underwear). The risk is perceived as an "unknown risk".
Some women seem to have partial or unclear knowledge on the subject. They are therefore less informed, as these words testify: "You can't say that there are no risks, we all know that there are risks in wearing second-hand underwear. We can have infections for example (Extract from an interview with Mr. D, a user of second-hand underwear at the SicogiAbidjan market).

As for second-hand underwear traders, some believe that there is no risk in using thrift store boxers. This posture can be understood either by ignorance or under the protection of their economic interests. Indeed, the objective of the latter being to profile, they don't care about what their goods may be a profile, they don't care about what their goods may be a profile, and they don't care about what their goods may be a profile danger for women. This is evidenced by these statements:

It's been 5 years since I've been at the "djassa" and I've been selling nothing in it. When it leaves in Europe there and then we're going to take it in the balls there, it's already washed, treated there before arriving here. Even if there's disease in it, we sell it's our job, we can't tell someone not to buy because there's disease in it (Extract from an interview with T.F., a second-hand underwear trader in Yopougon Sicogi).

Other traders on the other hand recognise the risks to which women are exposed However, they develop ideologies of individual choice. This is illustrated by the following statement: My brother it's a thrift store, everybody knows that it doesn't come from here, we don't know who to wear before, so if they come to buy here they know why they come to buy it.

\section{(Extract from an interview with F. A, a second-hand boxer shorts user).}

This confirms the idea that the persistence of behavioural patterns at risks related to the use of second-hand underwear is due to the low level of knowledge of the populations. Lack of awareness of the concept of "santé" by respondents. The rules the basic health elements that contribute to the preservation of the individual's state of health are only therefore not perceptible in the behavioural habits of the population.

\section{Assumed control of health risks and ideologies of non-exposure to health risks}

Sterilization procedures are the practices or methods used to treat pants. Used clothing before use to eliminate hazards. They consist of a set of processes which consist in making thrift store pants more hygienic. This practice gives women of Yopougon Sicogi a certain assurance of being safe from danger, they think thus controlling the risk. This leaflet illustrates this content well: I disinfect very well before wearing. I first soak in bleach. I wash with soap, rinse 
and then it's finished, there is no more danger (Extract of maintenance with D. M, user of second-hand pants).

In the light of these comments, we note that these women are unaware that even with the washing, the risk still exists. There are fungi such as "candida albicans" responsible for the scabies that resist very high temperatures. The risk is thus perceived as a "controllable risk with reduced exposure" and the feeling of individual control of the risk partly explains the minimisation of these risks.

\section{Risk/effect ratio}

The risk/effect ratio is one of the factors accounting for certain risk behaviours. In fact, the representation of the perceived risk depends in this context on whether or not the danger has an immediate effect. Risk is perceived as very dangerous depending on whether the effect is immediate and vice versa. The use of second-hand pants can therefore be explained by this principle, as shown by these remarks:

In all this, I'm saying that something that's dangerous even when you see that when you're doing it at the same time it can kill you, you're not going to do it, otherwise we wouldn't wear second-hand underwear, which is sure it doesn't kill Africans (Excerpt from an interview with D.M., a user of second-hand underwear in Yopougon Sicogi).

Analysis of the results shows that the women of Yopougon Sicogi are unaware of the damage linked to the use of second-hand pants and think they can control the risk, minimise and repress the danger through the non-immediate effect. The low level of Knowledge of the health risk of the use of second-hand pants leads women in Abidjan to perceive the health risk as "an unknown, controllable and non-immediate risk". In short, the risk is perceived as low or unimportant, and as a result repel its dreadful. Information and education on risks must enable public opinion to "better perceive risks", to demonstrate a "culture of risk", to abandon its irrationality and imaginary fears. "What we should fight above all is ignorance of our own ignorance" [3].

\section{Ideologies of risk acceptability developed by women as a factor in representing the health risk of the use of second-hand underwear}

The concept of risk acceptability involves the perception of risk, care activities and risk management policy by individuals. This is why the fields of health care governance and health democracy are closely linked to the concept of risk acceptability. In the social construction of reality, Peter Berger and Thomas Luckmann examine the problem of legitimisation. According to them, it is a second-order objectification of meaning that serves to integrate already existing meanings attached to disparate institutional processes.
The problem of legitimation will expressly arise when there is a transmission of the institutional order, legitimation then becoming both a process of explanation (cognitive) and justification (normative) resulting in differential ideologies.

\section{Ideologies relating to economic constraints and quality as a factor risk acceptability}

His ratio to price is a plausible antecedent to the use of thrift store underwear in the women of Sicogi. For a long time, the "low price" factor has always been a factor that has motivated women to rush to buy and use thrift store underwear. Thus it is a constraining social phenomenon linked to the register of impoverishment. This state of affairs forces them to combine it with the health risk. We are therefore witnessing the symbolic domestication of risk. This presupposes that we are capable of "dealing with risk", of finding good reasons to live with it and in spite of it. The risk is thus perceived as a "constraint". These remarks are illustrations: We're going to do how, that's what's cheaper, that's why we're in it (Excerpt from an interview with K.S., user of a second-hand underwear shop). This statement illustrates:

If women come to buy second-hand underwear it is because it is cheaper. When you break a ball like that, they come here a lot and it doesn't last forever. With only 1000 francs you can collect a lot of underwear (S. $\mathrm{D}$, a second-hand underwear trader at the Yopougon Sicogi market).

Second hand clothes are a garment to which the women of Sicogi attach a particular representation that makes its use an invaluable choice. This is undoubtedly due to the models representing the origin of second-hand pants, the result of a social category common understanding as defined by Geog Simmel, i.e. the common opinion of the commonly received. "Everything that comes from Europe is of good quality".

This representation attached to second-hand pants is also determined by the textile used to make them. These are garments generally made of cotton fibres, a highly prized material that meets the quality criteria of a garment. Durability is also a value given to second-hand underwear. Second hand pants are therefore equated with quality. You can see this in the words of this woman: I buy second-hand pants because they are of good quality and they are made of cotton. I buy for myself and for my children. It's better than the new Chinese boxers that don't even last (Extract from a conversation with T.M., user of thrift store pants).

\section{Ideologies of addiction, factor of acceptability of health risks}

What replaces instinct in man, and therefore allows him to direct and specialise the activity, is habituation. Indeed, any action repeated in a model can 
blend into a pattern and be reproduced with little effort. These actions restrict choice, they free the individual from the weight of decisions. They provide a stable background from which meanings emerge and become pre-data, allowing a foreground to allow for innovation and reflection. Women's habit and experience with the use of second-hand underwear makes them feel safe from the historical and institutionalized nature of the behaviour. Risk is thus perceived as a "familiar risk". They therefore do not associate any risk with this behaviour or even think about it when it comes to the use of pants. The fact that these are second-hand clothing stores is reflected in these remarks:

If these are thrifty shorts, I've worn them too much. I have always worn these and I have nothing to do with it, so I don't think it could give me a disease, but I don't think it would give me a disease for a long time. (Extract from an interview with

T.A., a 23 year old user of second-hand underwear).

We can see that the little feared risks are those practised on a daily basis. Women therefore minimise the health risks of using second-hand pants. The risk is perceived as a "familiar risk".

\section{Ideologies based on the social learning of health risk within the family environment and with peer groups}

To study the influence of interactions with significant others, we rely on G. H. Mead's theory of socialization. It can be summarized as follows; by being born within an objective social structure, the individual encounters significant others who take care of his socialization. The presence of these significant others, their definition of reality (which is based on filtering) imposes itself on him. This primary socialisation is not only cognitive, it also takes place in a strong emotional context, and by identifying emotionally with others, the child internalises the attitudes and roles of significant others, which enables him/her to acquire a subjectively coherent and plausible identity. The ego is then a reflective entity.

Reflecting the attitudes first adopted by other significant others, the individual becomes the image that others have of him or her. Identity, subjectively appropriated by the child gives it a place in the social world, therefore it will internalise both the social world and its identity. Gradually, this socialisation will move towards higher and higher levels of abstraction, it will thus abstract the roles and attitudes of others through a generalised Other. Through this generalised identification, the individual stabilises his or her selfidentification and internalises society as such. This double process implies that identity and reality are internalised in the same movement, there is a creation of a symmetrical relationship between objective and subjective reality, what is real "outside" corresponds to what is real "inside". Thus, in the course of their socialisation, some women in Sicogi have internalised the appropriation of thrifty pants in their wardrobe. This behaviour is part of a social learning process that takes place through imitation of the behaviour that the parents show to the young girl. In fact, these women, who have always had experience of the second-hand underwear that their mother or sister or aunt etc. used to use and which they were also given to use, have unconsciously familiarised themselves with their use, which has become a tradition.

We are therefore witnessing an institutionalisation of this practice of re-employment legitimised by the family. This is well illustrated by the following comments: Since I was little I've been wearing second-hand underwear. My mum used to buy them when she went to the market and then at home everyone wears them ( Excerpt from an interview with A.J., user of second-hand underwear). This socialisation is on a second level. It is called "secondary socialisation.

According to Merton, in this context, the use of second-hand pants is the result of the internalization of this practice outside the family framework. The groups of friends with whom the women of Sicogi interact are likely to exert an influence on them. Within a circle of friends, the women can make use of secondhand underwear. This generalisation of behaviour within the group will influence women who did not use them. Motivations can be created in the forms of conversation that guide women to use second-hand underwear. In the following, we see this relationship:

You can buy second-hand underwear there if it's not now, I didn't wear them before...I didn't like it when I saw people selling...I saw my friends wearing them but it didn't tell me what they were wearing. One day, my friend told me to go with her to buy something too, she said it's good, it lasts like that, and then I saw it's heavy, it's cotton, it's pretty too, so that's why I chose two and then I started to wear it (Extract from interview (1) with N.T., a second-hand underwear shop user).

With regard to the presence of significant others, the risk is perceived as a "collective risk".

\section{Ideologies attributing health risk to divine will}

This approach in the Durkheimian sense of the term conceptualised "the substantialisation of the Social" postulates that everything that happens on earth is the work of a superior, invisible being. Postulating the goodness of God and that everything that happens on earth is the result of his work, the women of Sicogi consider the danger that the use of thrifty pants could contain as a divine choice and accept it as a consequence; "everything God does is good", "it is God who gives health".

This conception therefore leads them to disengage from prevention. There is no point in 
preventing health if it is God who gives. The risk is therefore perceived as "dependent on the divine will" These words illustrate this content:

For me, we shouldn't be afraid to use thrifty pants so I think that here on earth there is no danger at our level because God decides everything. Someone can use used used underwear and then he is healthy and another person can use new underwear and get sick. So if you are going to get sick, it is God's will, and as God is good and loves his children, you will not get sick too (Excerpt from an interview with G.M., a second-hand underwear user).

In short, the use of thrifty pants by the women of Yopougon Sicogi is reflected in their representations of risk. The ill-informed individual therefore does not have cultural capital in the Bourdieuusian sense of the term to take action to guarantee his state of health, (ii) the weakness of the culture of prevention. The low level of scholarly culture and the predominance of popular knowledge (ideologies) account for the persistence of risk behaviour.

To put it plainly, there is a low level of general knowledge and a prevalence of popular knowledge among the populations responsible for the low level of health awareness, with disastrous consequences for the general development of Africa and responsible for health underdevelopment in general. We can therefore deduce that it is popular knowledge which conditions "the attitude and behaviour of individuals with regard to disease and, in particular, with regard to prevention" [16]. The lack of knowledge of health risk and the ideologies of acceptability of health risk developed by the women of Yopougon Sicogi contribute to the construction of their representations of the health risk linked to the use of second-hand pants and thus legitimise their behaviour.

For [17], "this low health awareness in relation to the weakness of the culture of prevention can therefore be explained by the history of this continent whose medical knowledge has made limited progress compared to popular knowledge. This has been the case because it is always the development of experimental knowledge that drives a general level of knowledge, which is translated into a level of health awareness".

This is why he states that "the delay in health development in Africa is primarily due to the lack of knowledge of health among the African people". It is this popular knowledge that more or less strongly conditions "the attitudes and behaviour of individuals towards disease and, in particular, towards prevention".

All in all, the low level of knowledge of the health risk of using second-hand pants and the ideologies of risk acceptability developed by the women of Yopougon Sicogi lead them to perceive the health risk as an unknown risk, controllable with reducible exposure, with a non-immediate effect and non-fatal consequences, a risk which is binding, collective, familiar and dependent on divine will.

4-5-Socio-cultural weighing of the risks of the use of second-hand pants

According to [18], "Individual behaviours generally take place within the framework of commonsense social thinking and practices rooted in a habitus as an incessant and largely unconscious process of learning and inculcation, which would direct the individual to think, act and perceive his or her experiences according to internalized patterns, inculcated through learning or socialization. But also, and above all, a habitus as a set of predispositions varying according to the nature of the risk and its contexts of emergence, as well as "an infinite capacity to generate in complete (controlled) freedom products of thoughts, perceptions, expressions, actions which always have as their limits the historically and socially situated conditions of its production.

Risk behaviours are therefore part of lifestyles, habits, social practices, secular strategies for managing choices in a context of uncertainty; in short, as negotiated, on a daily basis, by an individual with multiple complementary rationalities and open to dealing, in a reflexive framework, with certain risks in certain circumstances". Women's recourse to secondhand pants is therefore explained by a principle of habitual use of these pants, thus forming part of their lifestyles and daily practices. This is illustrated in this case:

Since the age of 10 , my parents have always bought second-hand clothes for me. I dress in second-hand clothes. They are quality and durable clothes. So, today I continue to dress in second-hand clothes from secondhand shops. I feel comfortable when I dress in secondhand clothes (F.M, Yopougon, January 16, 2020 at 3 p.m.).

To raise the price: The use of second-hand clothes is now part of our way of life (N.Y, Yopougon, and January 16th, 2020 at 4 pm). These findings are in line with the results of the study [19] which show that: "Risk behaviours are part of a social learning process about danger which takes place through two mechanisms: imitation of the behaviours that parents show their children and imitation within peer groups. Every individual in the process of physical and intellectual development undergoes socialisation through the internalisation of the exterior. The primary socialisation that takes place in the family setting allows the child to incorporate the parental behaviours that he observes and according to which he guides his own behaviour and a certain number of basic skills and values. Then, secondary socialisation, which takes place through reference to a social group, influences behaviour. An individual in a configuration of addicted 
people is likely to adopt the same behaviour as his peers because he is unconsciously influenced by the overall behaviour of the members of the group. Consequently, this generalisation of behaviour within the group will give the individual an assurance that he or she is safe from danger, hence the weakening of the perception of risk".

Thus, we can agree that the use of second-hand pants is linked on the one hand to the fact that parents have also generally used second-hand shops and on the other hand to the fact that the individual's entourage uses second-hand pants, which will reduce or eliminate the fear of health risks linked to the use of second-hand pants. In the light of the above-mentioned observations, it should be stressed that perceptions therefore guide the behaviour of second-hand goods consumers. We therefore note that the use of second-hand underwear by women is linked to their perception of second-hand underwear as not involving any risk. By ricochet [20] stipulate that: "Health behaviours are social behaviours conceived schematically as functions of the attitudes and beliefs of individuals and groups in relation to objects or situations. These behaviours therefore reside in divergent rationalities, or even in an ethno-ethics of the social construction of threat and moralisation of life habits". Thus, the use of second-hand pants is conditioned by the representations which women make of the product in order to legitimise it.

In this same system of social influence of behaviours [21], maintains that: "Risk behaviours are linked to the degree of familiarity with risk, a consequence of experience or habit. Moreover, the influence of the peer group influences behaviour. Some risk behaviours are often experienced by several people and would probably not be adopted in a solitary way, which implies the influence of the presence of others on the way risk is represented. Being in a group makes you feel safe. There is also a feeling of euphoria in the group: one is doped up by what the others are doing, it is enough for one of them to pass by, and we all follow, we don't even think about it any more.

In addition to this, the group also provides an objective view of the level of risk involved". On the basis of this thesis by (M. Cécile, idem), let us note that the use of second-hand underwear by women is motivated by the fact that the groups of relations in which they are involved use second-hand underwear, which mechanically reassures them and removes the fear of the danger incurred. This is illustrated in this case:

Many women wear the thrifty pants. I have not yet heard any complaints about any risk of contracting any disease through the use of second-hand underwear"

\section{(T.C, Yopougon, January 17, 2020 at 10 am).}

These findings show that women's relationship to their socio-cultural environment legitimises their perceptions of risk behaviour in the use of second-hand underwear. It could be said that women's relationship with their family, friends and social environment, so to speak a relational and organisational intermediation, influences the use of second-hand underwear. It is important to remember that risk behaviour is also determined by social and cultural factors. However, these approaches, which focus on socio-cultural determinants, reduce the intervention and responsibility of the individual in risk-taking. Does the level of health awareness influence health risk behaviours?

\section{Degree of health awareness}

The individual's relationship to his or her health is an important factor in the development of health risk behaviours. According to [10] "in their practices, actors expose their health or that of society not because they do not have an instinct for selfpreservation, but simply because they do not know that they are running risks to their health or that of the environment to which they belong". What is at issue for (S. Dedy, idem), "is fundamentally the low level of scholarly culture, the predominance of popular knowledge. It is this popular knowledge that more or less strongly conditions the attitude and behaviour of individuals with regard to illness and, in particular, with regard to prevention. Ignorance kills because it misleads; conversely, knowledge saves because it takes us from the stage of instinctive prevention to that of the culture of prevention".

It should be noted that lack of knowledge of health risks influences the use of second-hand underwear. If secondhand pants were a source of disease, we wouldn't have sold our clothes on the market (S.A, Yopougon, 21 January 2020 at $10 \mathrm{am}$ ); "There is no zero risk in everything we consume. We disinfect our shorts with bleach before wearing them. I think we are now safe from any danger" (K.A, Yopougon, 28 January 2020 at $4 \mathrm{pm})$. According to [21], "The magnitude of danger is an important variant of risky behaviour. It makes it possible to distinguish the accident (great danger) from the incident (slight danger). There may be danger without much risk, but if there is no danger, there is no risk. Individual and collective pipelines are thus constructed schematically according to the level of perception of danger. It is obvious that a social actor who is better informed about the dangers of a given reality does not develop the same behaviours as one who has never heard of it or who is less informed about the dangerousness of the phenomenon".

The use of second-hand pants is therefore linked to a poor knowledge of the associated danger. In the same vein [22] maintain that: "Risk behaviours are guided by the degree of danger perceived by social actors. Thus, nothing is a risk in itself; there is no risk in reality. But on the other hand, anything can become one; it all depends on how one analyses the danger and considers the event" [23]. Since the perception of danger is a social construct, all individuals have a 
differential conception of what is dangerous and according to which behaviour is oriented. The use of second-hand pants is therefore guided by a low level of knowledge of the associated danger by women in the Sicogi market. By ricochet, [24] consider that: "The judgement of risk is not influenced by probabilities and utility, but is a function of fear linked to catastrophic potential and the degree of knowledge of the risk. This position therefore poses a problem for health education insofar as ignorance leads social actors to develop behaviour that endangers their health.

The lack of information and awareness is a factor that influences risk behaviour". From this observation by (R. Kmiec and C. R. Levy, idem), it should be noted that the use of second-hand pants is thus explained by the low level of knowledge of the danger and the absence of fear linked to their use.

A study carried out by [25] on the relationship between health awareness and the consumption of street food in Yopougon Gesco suggests that the use of street food in the said area is a constraining social fact. According to this study, the populations are aware of the health risks linked to the consumption of street food. However, they minimise these risks by developing the ideologies of constraint associated with low purchasing power and the distance between their place of residence and their place of work. The use of second-hand pants is explained by a number of constraints although the women are aware of the danger involved. In general, it should be noted that individuals have a low awareness of health, which is the result of social and cultural perceptions and constraints.

\section{DISCUSSION OF THE RESULTS}

In total, this study examines a few ideological references that legitimise the use of second-hand pants among a category of actors. These ideological referents are often influenced by the perceptions maintained on the one hand by the actors and on the other hand, the socio-cultural space in which the actors evolve.

First of all, the study showed how popular perceptions and lived experiences of the use of secondhand pants articulate and interpenetrate to legitimise the actors' objective commercial choice. Secondly, it could be retained that the choice of second-hand underwear is based on a popular perception of the use of second-hand shops in general, which guides the actors' commercial behaviour. Above all, the use of second-hand pants is based on the degree of health awareness of the actors. It emerges that the main challenge is to minimise health risks within a cultural category from a survival perspective.

On this basis, the present study is close to the results of (Ruxanda, K \& Christine, R-L. [15] consider that: "Risk judgement is not influenced by probabilities and utilities, but is a function of fear related to catastrophic potential and the degree of knowledge of the risk. This position therefore poses a problem for health education insofar as ignorance leads social actors to develop behaviours that endanger their health. The lack of information and awareness is a factor that influences risk behaviour".

It emerges from the above-mentioned observation that women who use second-hand pants develop behaviours that legitimise the commercial relationship with the second-hand sellers on the one hand, and on the other hand develop ideologies for the construction of health risks based on cultural and socialisation values.

Indeed, the cost value of second-hand pants for the women interviewed does not constitute a constraint for women to buy new pants. From this angle, the results of this study do not concur with the findings of the study by [6] indicating that: "The devaluation of the CFA franc, the economic situation of the Abidjanese, who were already in a bad way, has worsened because of the socio-economic and political crises of the 2000s. The majority of Abidjanese therefore find themselves in financial difficulty nowadays. They are going to use all sorts of means of survival at the risk of their health or their lifestyle.

Moreover, the present results of this study have shown some socio-cultural burdens of the use of second-hand underwear. These ideological referents were, among others, the construction of health risks, socialisation, etc., and the use of second-hand underwear.

Moreover, in the context of the dynamics of the object of the sociology of sexual and reproductive health, one could not merge into a unilateral logic of interpretation of the use of thrift shops. In fact, the barriers which distinguish each of the popular and scientific knowledge of the purchase and use of secondhand underwear from each other and their internal homogeneity are brought back into evidence.

The use of second-hand pants is now at the centre of the analysis of sexual and reproductive health, for the preservation of the health of populations. In the light of the above-mentioned observations, it must be mentioned that cultural constraints are directly associated with the choice of second-hand underwear. In the same way, the use of second-hand clothing by social actors must be an important issue at the centre of scientific reflection in order to prevent diseases, a condition of life expectancy.

\section{CONCLUSION}

This study is a contribution to the sociology of sexual and reproductive health. It analyses some of the social factors that legitimise the use of second-hand pants by individuals. It was essentially qualitative, 
using appropriate survey tools. This enabled us to arrive at the results according to which the perceptions and knowledge of the actors are intertwined and legitimise their use of second-hand pants. In fine, it should be noted that the ideologies that actors construct around the use of second-hand pants constitute the inseparable element in terms of actors' behaviour and attitudes to minimising health risks. This idealisation of the use of second-hand pants is accompanied by an ethic on the part of actors belonging to the same socio-cultural field, with each actor demonstrating strong normative selfcontrol, thus limiting risk behaviours such as disinfecting second-hand pants before any use. Let us remember that the use of second-hand pants is linked to ideologies that we can describe as 'ignorance' which allow actors to build self-confidence by using secondhand pants. Nonetheless, the sharing of experiences between actors with regard to the cost and quality of second-hand boxer shorts fabrics helps to consolidate or legitimise a commercial relationship.

\section{REERENCE}

1. Williams, C. C., \& Paddock, C. (2003). The meanings of informal and second-hand retail channels: some evidence from Leicester. The International Review of Retail, Distribution and Consumer Research, 13(3), 317-336.

2. Charpy, M. (2002). Formes et échelles du commerce d'occasion au XIXe siècle. L'exemple du vêtement à Paris. Revue d'histoire du XIXe siècle. Société d'histoire de la révolution de 1848 et des révolutions du XIXe siècle, (24), 125-150.

3. Bertolini. G. (2005). Les vêtements d'occasion et leurs pérégrinations. Géographie et cultures [En ligne], 56, URL: http://journals.openedition.org/ gc/8709; DOI : https://doi.org/10.4000/gc.8709.

4. Bredeloup, S., \& Lombard, J. (2008). Mort de la fripe en Afrique ou fin d'un cycle? Colin « Revue Tiers Monde ». N² 194 p 291-412.

5. Diabagaté, A. (2015). Le tronçon routier Agbancarrefour zoo à Abidjan: une galerie marchande. Revue de géographie Tropicale et d'environnement, $\mathrm{N}^{\circ} 2$.

6. Bamba, L. (2012). Risques sanitaires des produits de la contrebande sur la vie des populations d'Abidjan. Revue Africaine de criminologie, EDUCI, 24-35.

7. Roux, D. (2007). La résistance du consommateur: proposition d'un cadre d'analyse. Recherche et Applications en Marketing (French Edition), 22(4), 59-80.

8. Wera, M-S. (2018). Analyse des barrières à la consommation des vêtements de seconde main, Master en sciences de Gestion, à finalité spécialisée en Marketing, HEC-Ecole de gestion de l'Université de Liège.
9. Roux, D. (2006). Am I what I wear? An exploratory study of symbolic meanings associated with secondhand clothing. ACR North American Advances.

10. Séri, D. (2008). Pratiques à risque pour la santé et conscience sanitaire des populations en Afriques subsaharienne : cas de la Côte d'Ivoire. Cash. Santé Publique. vol 15. N²-2016 @EDUCI.

11. Berger, Peter L., \& Luckmann, T. (1966). La Construction sociale de la réalité, trad. fr.1986, rééd. Armand Colin, coll. « Références ».

12. De Bruyn, M., \& McCart, P. (1974). Life history of the grayling (Thymallus arcticus) in Beaufort Sea drainages in the Yukon Territory. Biometrics, 2, 1-42.

13. Moscovici, S. (1976). Studies in social influence III: Majority versus minority influence in a group. European journal of social psychology.

14. Van, C., et Quivy, R. (2011). Manuel de recherche en sciences sociales, $4 \mathrm{e}$ édition, entièrement revue et augmentée, Paris, Dunod.

15. Kmiec, R., \& Roland-Lévy, C. (2014). Risque et construction sociale: une approche interculturelle. Les cahiers internationaux de psychologie sociale, (1), 6999.

16. Massé, R. (2007). Le risque en santé publique: pistes pour un élargissement de la théorie sociale. Sociologie et sociétés, 39(1), 13-27.

17. Séri, D. (2010). Culture, histoire et santé : la conscience sanitaire comme composante de développement de l'Afrique. Colloque international pluridisciplinaire, Yamoussoukro, Côte d'Ivoire. 24 pages.

18. Bourdieu, P., \& Nice, R. (1980). The production of belief: contribution to an economy of symbolic goods. Media, culture \& society, 2(3), 261-293.

19. Assailly, J.P. (2006). Les conduites à risque des jeunes : un modèle socioséqentiel de la genèse de la mise en danger de soi, Revue psychotropes, 2 ; 49-69

20. Apostolidis, T., \& Dany, L. (2012). Pensée sociale et risque dans le domaine de la santé : le regard des représentations sociales, Université de Marseille, France

21. Martha, C. (2002). Etude du sens des risques actuels. Université de la Méditerranée, 3 N 77 ; 55-68.

22. William, D., \& Danielle, S. (2013). Agir face aux risques sanitaires. Hors collection. PUF ; 248.

23. Laurencin, C. T., Zelicof, S. B., Scott, R. D., \& Ewald, F. C. (1991). Unicompartmental versus total knee arthroplasty in the same patient. A comparative study. Clinical orthopaedics and related research, (273), 151-156.

24. Kmiec, R., \& Roland-Lévy, C. (2014). Risque et construction sociale: une approche interculturelle. Les cahiers internationaux de psychologie sociale, (1), 6999.

25. Vonan, P. C., \& Agobé, J. (2015). Conscience sanitaire et consommation de la nourriture de rue au marché de Gesco. Anyasa. Université de Lomé; 4. 